Published in "International journal of hospitality management", 2019, vol. 76, part A, pp. 39-42, which should be cited to refer to this work.

DOI : $10.1016 / j . i j h m .2018 .02 .021$

\title{
1 THE ASSET LIGHT MODEL: A BLIND SPOT IN HOSPITALITY 2 RESEARCH
}

\section{INTRODUCTION}

4 This research note raises the question of the lack of critical appraisal of the asset light model. Its 5 purpose is to trigger an in-depth exploration of the determinants of performance of the

6 implementation of such a model. The decision to divest properties and specialize in operations (i.e.

7 the asset light model) has become a widespread practice amongst hotel corporations (Figure 1) and 8 is often presented as the best fit for the organization (The Economist, 2013; Nair, 2014; Host and

9 Marriott 1994 annual reports). This practice, whose advantages have been widely reported 10 throughout academia, is becoming the new norm (Figure 1). The near universal acceptance of this 11 model makes the dubious assumption that an asset-light strategy is the best fit, in terms of 12 performance, for every organization in the hospitality industry.

Figure 1: The implementation of the asset light model

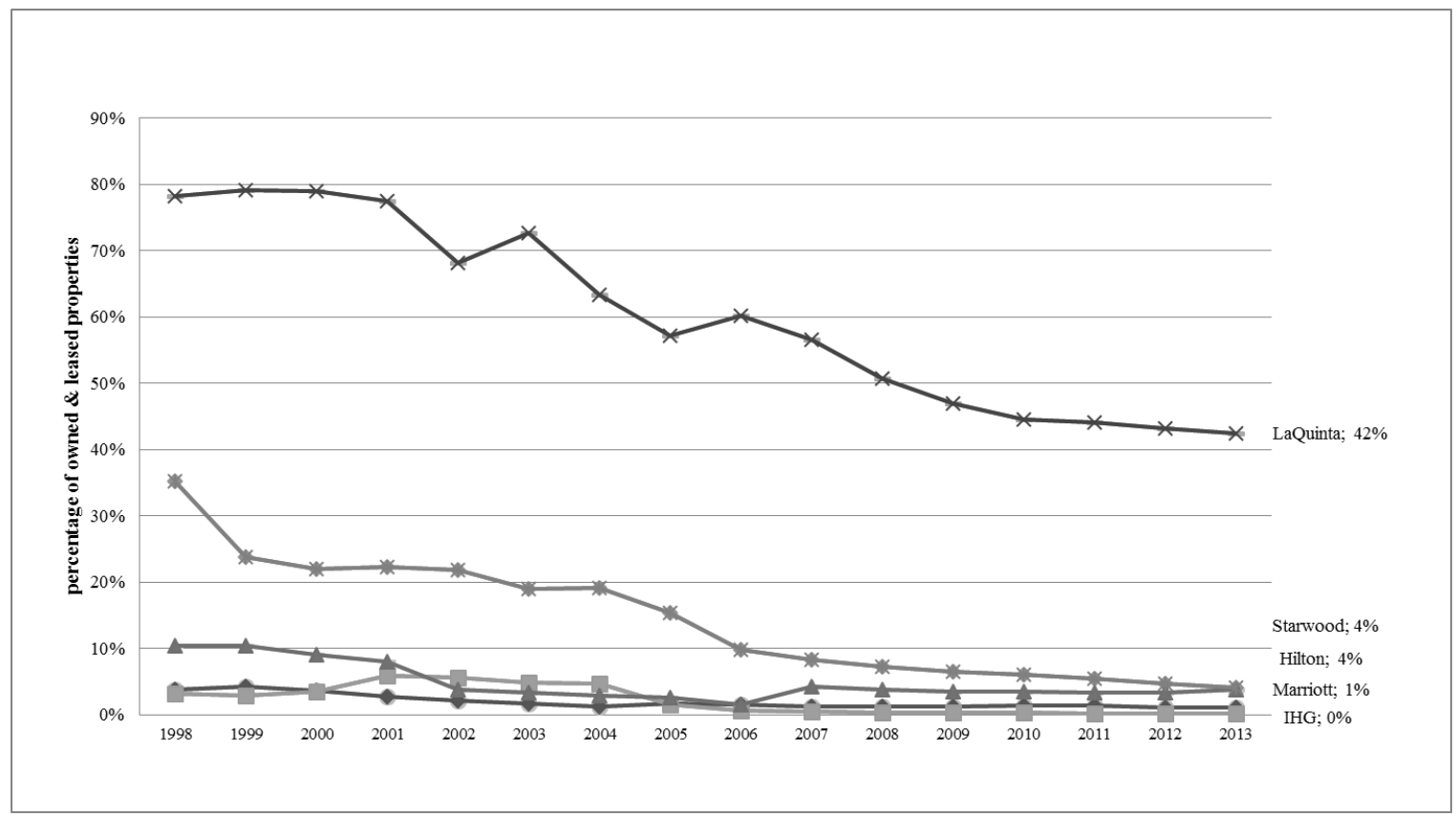

15

16 Source: Annual reports of respective companies. 
17 This assumption contradicts the fundamental principles of strategy, whereby unique choices (of competencies and positioning) are what drives outperformance (Wernerfelt, 1984, Porter, 1979). Blindly accepting the asset light model as the best option for lodging corporations leads practitioners and academia to overlook strategy fundamentals and ignore the consequences of the model on long-term performance. This blind spot in our approach to the issue prevents us from

22 addressing key questions such as, for instance, how to position the company vis-à-vis differentiation. Unfortunately, the lack of critical appraisal of the model is an obstacle to acquiring this knowledge.

Since it is accepted as the best choice for all companies, the asset light model and its effects on long-term performance is the subject of very few papers in tourism and hospitality research. These studies, with the exception of one (Low, Das, and Piffaretti, 2015), converge to confirm that the model is beneficial to corporate performance, which begs the question: How can just one divestment model be beneficial to the performance of all companies? Not to mention that companies implement it to different degrees, so what are the contingent variables which moderate the effects? Why are some companies more successful in generating superior performance than others after the implementation of the asset light choice? It appears that academia and executives are wearing blinders when it comes to this model. We hope that this research note will trigger more discussion for a more critical view of the asset light decision with a view to providing valuable insights for both academia and corporate practices.

\section{EPISTEMOLOGICAL ISSUES}

37 There are, however, practical aspects that explain the limited empirical research on the subject. The most important is the limited size of the population. The asset light model goes hand in hand with network size, which limits the number of hospitality corporations from which to collect data.

40 The latest wave of mergers and acquisitions further exacerbates this limitation. Nevertheless, the

41 blind spot that the asset light model represents is of an epistemological nature for three reasons.

42 First, the justification for the asset light model is, most often, based on ex-post interpretation and 43 industry reports rather than scientific research. Articles argue that the model allows organizations 
to adapt to macroeconomic changes such as modifications in debt market conditions and fiscal 45 regulations on real-estate (Blal \& Graf, 2013; Hudson, 2010). It also an attractive option to enter new markets (Brookes \& Roper, 2012; Roper 2015), and a tool to mitigate risk (Sohn, Tang \&

47 Jang, 2013). Furthermore, practitioners and financial investors argue that it enables companies to 48 diversify their risk profiles (Page, 2007). However, with the exception of three studies (Sohn et al. 2013 and 2014; Low et al. 2015) on the impact of asset light on firm value, we have no scientific investigation of the performance benefits supposedly generated by the model.

51 Second, the few empirical studies that have evaluated the financial impacts of the model indicate 52 that increasing the ratio of franchise and management fees to total sales and decreasing the 53 proportion of fixed to total assets has a positive impact on firm value (Sohn, et al., 2013 and 2014). 54 Nevertheless, using to the portion of revenues to operationalize the asset light model overlooks its effects on organizational design. Also, it does not factor in the impact of specialization. The study by Low et al. (2015) measures the role of hotel properties' asset class in mixed asset portfolios. 57 The results reveal that lodging corporations that own their property assets outperformed organizations that had chosen an asset light model. These findings converge with articles in finance literature, which reveal that the asset light model has a negative scale effect (Yu and Liow, 2009) and a limited effect on performance.

61 Third, the asset light model entails a deliberate choice to specialize in one or more points along 62 the value chain (Blal and Graf, 2013; Roper, 2015) and makes concurrent use of ownership 63 transactions, leasing, franchising, and operating contracts. Therefore, its implementation requires 64 the reliance on flexible organizational arrangements that make simultaneous use of transactions. 65 Such lean and complex structures are very likely to increase coordination and operating costs, and 66 thus, hinder the overall operational performance. Not to mention that not all companies in the 67 industry have these skills. We propose that adopting the asset light model is a way of adaptation to a norm, but that its effects on performance are neither uniform across corporations nor immediate. Therefore, considering this model as a one-size-fits-all solution is a fundamental flaw that hinders the progression of research and contribution to management. 
72 The goal of our analysis is to examine whether the implementation of the asset light structure

73 affects the financial performances in the lodging sector. The literature makes the link between

74 financial markets and the asset light model. Therefore, we selected companies that are listed on

75 the New York Stock Exchange and that pursued an asset-light strategy over of period of at least

7615 years. As the implementation of the asset light model started in the mid-1990s, we could observe

77 the phenomenon over a 16-year period from 1998 to 2013. The mid 1990s marks the inception of

78 the phenomenon.

79 The restructuration, mergers, and acquisitions that occurred in the industry limited the number of 80 companies available for the longitudinal analysis. Six corporations constituted the available 81 population for our research: Marriott, InterContinental, Starwood, Hilton, Choice, and LaQuinta.

82 In addition, the panel data is imbalanced: out of these six corporations, we could collect the 83 financial data of two (i.e. Choice and Starwood) for the whole period from 1998 to 2014.

84 To explore our argument, we examined the effects of the asset light model on three performance 85 measures (i.e. the return on share price, Earnings before Interest, Debt, and Amortization-EBITDA, 86 and Return-on-Equity-ROE) of six leading U.S. corporations over the 1998-2013 period. We used 87 a longitudinal data design that combines both cross sections and time series. We did so to control 88 for unobservable variables, such as corporate culture, that do not change from one year to another. 89 From CRSP/Compustat Merged Database we obtained financial data at a fiscal year frequency. 90 We also used the data provided by Dr. French on his website to apply the Fama and French model 91 to compute the stock returns. We manually retrieved the total number of hotels in the corporation's 92 network and the number of managed and franchised hotels from the annual reports of the five 93 leading lodging corporations. To address the limitations of past studies, we operationalized the 94 construct of implementation of asset-light, by measuring the number of managed and franchised 
95 properties over the total number of hotels in the corporation's network ${ }^{1}$. This variable, as opposed to the revenue proportion used in the literature, integrates organizational design aspects. We started

97 collecting this information seven years ago, which allowed us to constitute a unique dataset on the asset light model.

To conduct our analysis, we use a longitudinal data design that combines both cross sections and time series to account for heterogeneity across panel units. The model controls for unobservable variables that do not change from one year to the next (e.g. business practices, or a firm's corporate culture, etc.). Based on the results of the Hausman test, we adopted the random effects model $^{2}$. We also confirmed the robustness of our results using the fixed effects model. Finally, our model had the following specificities:

$$
\text { Performance }=\propto+\beta_{i, l} \text { light }_{t-\text { lag }, i}+\beta_{2} X_{i, t}+\varepsilon_{i, t}
$$

We included a vector of measures to control for financial, economic, and operational characteristics (Table 1). Specifically, in the EBITDA model, we included four control variables. First, growth, that controls for the period-to-period difference of the log transformation of U.S. G.D.P. in nominal dollars. Data was retrieved from the Graduate Institute of International Development Studies (GIIDS). The variable accounts for the overall macroeconomic evolution and measures the change in performances due to a change in the business cycle. Second is the 112 inflation level in the U.S. where data was obtained from GIIDS. Third is the total number of 113 properties in the company's network. Finally, we introduced a year dummy for each year.

114 In the stock return model, we measured the percentage change in the stock price estimated with 115 the Fama-French model. When we used the return on stock price s a measure of performance, we 116 controlled for the liquidity (i.e. total cash available at the end of the fiscal year) and a measure of

\footnotetext{
${ }^{1}$ Formally, the explanatory variable of interest is defined as: light $=\frac{(\# \text { Management properties }+\# \text { Franchise properies })}{\# \text { totals properties }}$
}

\footnotetext{
${ }^{2}$ In terms of significance the random effects model generates similar results compared with the fixed effects model.
} 
117 leverage (i.e. total liabilities over total assets). When we used ROE to operationalize performance, 118 we controlled for the total number of properties, leverage, and market capitalization.

120 Table 1: Multivariate analysis of the short-term effects of asset light structures on financial 121 performance.

\begin{tabular}{|c|c|c|c|}
\hline & In ebitda & Return & ROE \\
\hline $\mathrm{rf}$ & & $\begin{array}{c}0.00465 \\
(0.05)\end{array}$ & \\
\hline mktrf & & $\begin{array}{c}0.0144 * * * \\
(5.14)\end{array}$ & \\
\hline $\mathrm{smb}$ & & $\begin{array}{c}0.0141 \\
(1.38)\end{array}$ & \\
\hline $\mathrm{hml}$ & & $\begin{array}{c}0.00875 \\
(1.15)\end{array}$ & \\
\hline leased & $\begin{array}{l}-1.538 \\
(-0.08)\end{array}$ & $\begin{array}{l}-9.702 \\
(-1.17)\end{array}$ & $\begin{array}{l}17.11 \\
(0.53)\end{array}$ \\
\hline managed & $\begin{array}{l}-7.093 \\
(-0.75)\end{array}$ & $\begin{array}{l}-2.190 \\
(-0.55)\end{array}$ & $\begin{array}{l}11.62 \\
(0.79)\end{array}$ \\
\hline franchised & $\begin{array}{l}-6.774 \\
(-0.71)\end{array}$ & $\begin{array}{l}-2.125 \\
(-0.53)\end{array}$ & $\begin{array}{l}8.060 \\
(0.57)\end{array}$ \\
\hline owned & $\begin{array}{l}-6.208 \\
(-0.72)\end{array}$ & $\begin{array}{l}-2.417 \\
(-0.67)\end{array}$ & $\begin{array}{l}12.24 \\
(0.91)\end{array}$ \\
\hline growth & $\begin{array}{l}-0.140 \\
(-0.27)\end{array}$ & $\begin{array}{l}-0.0406 \\
(-0.27)\end{array}$ & \\
\hline inf & $\begin{array}{l}0.766 \\
(0.36) \\
\end{array}$ & $\begin{array}{r}0.153 \\
(0.24) \\
\end{array}$ & \\
\hline total & $\begin{array}{c}-0.000400 * * * \\
(-2.92)\end{array}$ & $\begin{array}{c}-0.0000130 \\
(-0.21)\end{array}$ & $\begin{array}{c}0.000341 \\
(1.45)\end{array}$ \\
\hline Cash & & $\begin{array}{c}0.000211 \\
(1.03)\end{array}$ & \\
\hline Leverage & & $\begin{array}{r}0.129 \\
(0.79) \\
\end{array}$ & $\begin{array}{l}0.187 \\
(0.21) \\
\end{array}$ \\
\hline market_cap & & & $\begin{array}{c}0.00000260 \\
(0.03)\end{array}$ \\
\hline _cons & $\begin{array}{l}14.41 \\
(1.56)\end{array}$ & $\begin{array}{r}1.977 \\
(0.51) \\
\end{array}$ & $\begin{array}{l}-8.643 \\
(-0.61) \\
\end{array}$ \\
\hline$N$ & 59 & 59 & 65 \\
\hline
\end{tabular}


Estimates are reported. $* * *, * * *$ indicate significance at $10 \%, 5 \%$ and $1 \%$ levels respectively. The t-statistic are

123 reported in parentheses.

124 The results are reported in Table 1. They show that the implementation of the asset light model 125 has no impact on the long-term performance of these lodging corporations. The total number of 126 properties in the network has a significant effect on performance, when measured with EBITDA. 127 In addition, the return on market portfolio is the only variable with significant effect on stock return.

\section{IMPLICATIONS}

Our purpose with this research note is to cast doubt on a phenomenon that pressures companies towards imitation and norms. We argue that the asset light model presents contingencies and has

132 limitations with regards to its effects on performance, which have been overlooked. We are hopeful 133 that this note will trigger further debate within academia and practitioners to support the creation 134 of new value-adding strategies for the hospitality industry.

135 Questioning this long-held assumption opens numerous avenues of investigation. First, the cost of 136 specialization and its effects on performance have been understated so far when, instead, this issue 137 could complement our strategy literature. Second, uncovering the contingencies of the asset light 138 model could help further research explore the organizational characteristics in play in terms of 139 boundary changes on performance. Having specialized hybrid structures reduces the risks 140 associated with operating or owning the business. Nevertheless, research indicates that this link is 141 contingent upon the nature of the activities, the complementarity of resources, and the access to 142 existing resources (Barney, Wright \& Ketchen, 2001; Mahoney, 2004). These factors can increase 143 coordination and controlling costs, which can lead to a reduction in overall financial returns. Such 144 investigation would contribute to both theory and practice as it would help organizations to decide 145 between implementing the asset light model or another alternative. Finally, future studies could 146 advance the field by examining the optimum mix of governance from a competencies standpoint 147 to support a competitive advantage. 
148 In conclusion, a critical stance on the implications of a model which is presented as the most fitted 149 for an entire industry can provide valuable insights for management and academia. For starters, 150 future research needs to empirically examine the long-term financial effects of the asset light 151 model. Also, it would be valuable for both industry and academia to study the optimal asset light 152 mix. Such research will enable companies to choose the type of contract, management contract, 153 franchise setup, leases or other new form of contractual relationship that will maximize its 154 performance. Also, in line with current advances in the strategic management literature, future 155 investigation could include company-specific variables such as competencies and internal factors. 156 However, this will only be possible if we dare to challenge the premise that just one model is the 157 best route for companies in an industry. 


\section{REFERENCES}

A short history of hotels: Be my guest. (2013, December 21). The Economist, Christmas special edition.

Barney, J., Wright, M., \& Ketchen, D. J. (2001). The resource-based view of the firm: Ten years after 1991. Journal of management, 27(6), 625-641.

Blal, I., \& Graf, N. S. (2013). The discount effect of non-normative physical characteristics on the price of lodging properties. International Journal of Hospitality Management, 34, 413-422.

Brookes, M., \& Roper, A. (2012). Realising plural-form benefits in international hotel chains. Tourism Management, 33(3), 580-591.

Host Marriott. (1995). 1994 annual report. Retrieved from https://www.sec.gov/edgar/searchedgar/companysearch.html

Hudson, K. 2010 Hotels posed to shed properties. The Wall Street Journal September, C11.

Low, W., Das, P., \& Piffaretti, C. (2015). The role of hotels in mixed asset portfolios: revisiting the asset-heavy versus asset-light debate. International Journal of the Built Environment and Asset Management, 1(4), 273-292.

Mahoney, J. T. (2004). Economic foundations of strategy. Sage Publications.

Marriott International. (1995). 1994 annual report. Retrieved from https://www.sec.gov/edgar/searchedgar/companysearch.html

Nair, S. (2014). Why InterContinental hotels' asset light strategy drives growth? Retrieved, March 26, 2015, from http://finance.yahoo.com/news/why-intercontinental-hotels-asset-light223805903.html

Page, T. (2007). 'Asset-Light'-Managing or leasing? Journal of Retail and Leisure Property, 6(2), 97-99.

Porter, Michael E. "How competitive forces shape strategy." (1979): 21-38.

Roper, A. (2015). Vertical disintegration in the corporate hotel industry. Current Issues in Tourism, 1-6.

Sohn, J., Tang, C. H. H., \& Jang, S. S. (2013). Does the asset-light and fee-oriented strategy create value? International Journal of Hospitality Management, 32, 270-277. 
187 Sohn, J., Tang, C. H. H., \& Jang, S. S. (2014). Asymmetric impacts of the asset-light and fee188 oriented strategy: The business cycle matters! International Journal of Hospitality 189 Management, 40, 100-108.

190 Wernerfelt, B. (1984). A resource-based view of the firm. Strategic management journal, 5(2), $191 \quad 171-180$.

192 Yu, S. M., \& Liow, K. H. (2009). Do retail firms benefit from real estate ownership? Journal of 193 Property Research, 26(1), 25-60. 